\title{
2 Are offsets effective? An evaluation of recent
}

*Corresponding author: Tel: +61 864884691

Email addresses: jelena_may@hotmail.com(J. E. May), richard.hobbs@uwa.edu.au (R.J. Hobbs), leonie.valentine@uwa.edu.au (L.E. Valentine)

Word count: Abstract 228 Text 7412

BIOLOGICAL CONSERVATION, IN PRESS

The use of environmental offsets has increased in many parts of the world over the last decade, but assessments of their effectiveness have been rare. We provide the first quantification of the effectiveness of offsets in an Australian State (Western Australia) with an offsets register and history of offset implementation. We determined what outcomes were achieved and the environmental effectiveness of 208 past and current offsets applied as part of environmental approvals between 2004 and 2015 under State jurisdiction legislation. Of the past offsets, we conclude that at most $39 \%$ of the offsets studied delivered an outcome and can be considered effective, with land acquisition comparing favourably to other offset types. The outcomes of many offsets were unknown due to reporting too soon after implementation (14\%) and inadequate reporting (18\%). Thirty percent of past offsets during this time period were found be ineffective through non- or inadequate implementation. We observed significant improvements in the clarity of offset approval conditions over the time period of our study, nonetheless, we suggest that these results provide evidence of the need for better implementation of on-ground management and research into the nature of offsets. We make four suggestions for improvement: 1) timely reporting and compliance with environmental conditions; 2) ensuring approval conditions measure ecological outcomes; 3) improving project planning for offsets; and 4) including contingency and longer term planning in offset design. Conclusions from examining implementation of offsets in Western Australia are likely to be applicable wherever offsets policies are in place or being developed.

Key words: environmental offsets, outcomes, environmental impact assessment, effectiveness framework, biodiversity offsets. 


\subsection{Introduction}

46

Environmental offsets ("offsets") are an increasingly used but controversial policy tool (Maron et al., 2015) to compensate for unavoidable development impacts on biodiversity (Business and Biodiversity Offsets Programme, 2009; Bull et al., 2013; Goncalves et al., 2015) or to provide net positive impact (Aiama et al., 2015). While much has been written on the advantages and potential pitfalls of the use of offsets in conservation policy (Maron et al., 2016), this has mostly been done in the absence of reliable information on how offset policies are working in practice. In this paper we provide one of the first evaluations of the effectiveness of a large number of offsets, in an area of great biodiversity value that faces rapid and ongoing resource and urban development.

The policy for modern offsets has developed in response to conservation concerns for biodiversity loss due to human development (Gordon et al., 2015; Fallding, 2014; Masden et al., 2010). Originally used in the 1970s as a form of biodiversity trading and banking for wetland and threatened species mitigation (Burgin 2008; McKenny and Kiesecker 2010), offsets are now frequently employed by many nations as part of environmental impact assessments (EIA; ten Kate et al., 2004). There are 51 offset schemes currently in use around the world (Ives and Bekessy, 2015). Principles and standard on offset implementation and verification have been developed by many jurisdictions, with commonly employed examples including: no net loss (or net gain/benefit), like for like or better, in perpetuity, averted loss and additionality (ten Kate et al., 2004; Business and Biodiversity Offsets Programme 2012; McKenny and Kiesecker, 2010).

Offsets are an appealing policy tool for mitigating environmental impacts because they may be used to provide compensation for impacts on biodiversity values, ecosystem function, ecosystem services, or all three (Bull et al., 2013). Despite the rapid expansion in the use of offsets, and the increasing interest from government, scientific, legal and community sectors (McKenny and Kiesecker 2010; Environment and Communications References Committee, 2014), there is considerable uncertainty about the outcomes of offset policies (Gordon et al., 2011; Gibbons and Lindenmayer, 2007). Use of offsets presents conceptual and practical challenges (Goncalves et al., 2015) and significant contested issues (Maron et al., 2016), but chief among these is understanding how (and if) offsets deliver on anticipated outcomes.

Relatively few examinations of effectiveness of offsets are available. Quetier and Lavorel (2011) outlined requirements for assessment of offset effectiveness, and other studies have recommended various approaches: for instance, modelling outcomes under different scenarios (Gordon, 2011) or comparison against a series of principles (McKenny and Kiesecker, 2010). Existing evaluations of offsets mostly relate to ecological function of wetland mitigation projects in North America (e.g. Brown and Veneman 2001; Sudol and Ambrose 2002; Matthews and Endress 2008; Moreno-Mateos et al., 2012) and regulatory compliance in New Zealand (Brown et al., 2013). The design and/or implementation of offset policies have been criticised for not producing the anticipated biodiversity conservation outcomes (e.g. Brown and Veneman, 2001; Quigley and Harper, 2006; Gibbons and Lindenmayer, 2007; Matthews and Endress, 2008; Teal 2011; Maron et al., 2012) and for infrequent successful examples (e.g. Pickett et al., 2013). Maron et al. (2016) highlighted the lack of empirical evaluations of offset schemes and identified the lack of available information about implementation and effectiveness as a key gap in offsets policy. 
94 Effectiveness has been considered in various contexts, including EIA (Pope et al., 2013), offsets policy (Gordon et al., 2011; Gordon et al., 2015; Moreno-Mateos et al., 2015), restoration offsets (Maron et al., 2012) and natural resource management programs (Pannell and Roberts, 2010); however there is no generally agreed definition for measuring effectiveness of offsets as they range across so many different types of projects. We propose that the effectiveness of offsets can be distilled to include three key concepts:

1. "Successful in producing a desired or intended results" (Oxford Dictionary, 2012);

2. The offset brought measurable, successful, long-term benefits; and

3. The benefit of the offset counterbalanced significant residual impacts or risk of a project (Government of Western Australia, 2014).

We examine these three concepts to determine if offsets imposed under Western Australian state jurisdiction have been effective. This approach constrains our examination of effectiveness to the technical and governance challenges described by Maron et al. (2016).

Where they are used around the world, offsets are generally imposed and administered under a regulatory framework. In Australia, similar to the USA and Canada, environmental regulation occurs in both State and Federal jurisdictions and includes impact assessment and mitigation measures. A wide variety of actions can be included as offsets in environmental approvals, such as environmental management, reservation of land (managed by public agencies or private organisations), restoration of ecosystems, research, or contribution to funds to achieve these.

Western Australia (WA) provides a unique opportunity for insight into offset effectiveness. Renowned for its floristic diversity and endemism, Southwestern Australia is a biodiversity hotspot, with $<30 \%$ original habitat remaining following extensive historic habitat loss associated with agricultural and contemporary ongoing urban development (Myers et al., 2000). Offsets for impacts on biodiversity have been in use in WA since the introduction of regulations on clearing of native vegetation in 2004 and release of Environmental Protection Authority position statements or guidance from 2006 onwards (Environmental Protection Authority, 2006; Environmental Protection Authority, 2008). The WA State Government has released a whole-of-government policy (Government of Western Australia, 2011) and comprehensive guidelines (Government of Western Australia, 2014; “Guidelines”). Here, as elsewhere, offsets form part of a hierarchy and are nominally resorted to once efforts to avoid and mitigate damage have been made. A focus on transparency and accountability regarding offset requirements in WA led to the development of a publicly accessible offsets register in 2013 ("the Offsets Register"; www. offsetsregister.wa.gov.au) to record the rationale, offset actions and spatial location of offsets (Government of Western Australia, 2014). The use of offsets in impact assessment and approvals, legislative frameworks and accessibility of data mean that WA provides an ideal location for study of offset effectiveness.

\subsection{Methods}

\section{1 Offsets included in the study}

All offsets included in this study were approved in WA during the period 2004 to February 2015 under the State Environmental Protection Act 1986 (EP Act). A total of 287 offsets were included in this study, and the effectiveness of a subset of 208 past and current offsets is reported. Most of these offsets were approved after July 2011 (consistent with data included in the Offsets Register). In Australia, there is overlap between threatened species and 
ecological community listings under Commonwealth and State legislation; however the offset requirements for each jurisdiction differ. Offsets are also applied for approvals under the Commonwealth Environmental Protection and Biodiversity Conservation Act 1999, including examples where the same offset has been used to satisfy State and Commonwealth legislation. However, to avoid issues of duplication and complications of evaluating effectiveness according to two approvals, we chose to include WA State EP Act approvals only.

We included the following offsets in our study:

a) All offsets listed on the Offsets Register as at February 2015, except ten clearing permits administered by the Department of Mines and Petroleum (for which detailed reporting information was not available at the time of analysis);

b) All other known offsets approved under EP Act Part IV; and

c) An additional16 offsets approved under EP Act Part V (which were included in a departmental internal review) prior to the establishment of the Offsets Register.

The methodology we used was as comprehensive as possible but did not attempt to include all offsets in WA as the terminology used within approvals documentation was inconsistent over time, particularly prior to 2011. We categorised the offsets according to offset types, design, implementation, evaluation and effectiveness.

Our study focused on the implementation and outcomes reported by approval-holders or compiled by regulators. We did not examine the validity of any assessment process or offset and did not conduct field verification. This obviously limits our examination of effectiveness, but provides the most complete analysis possible using publicly available information.

\subsection{Offset types}

We used the three offset types defined in the Guidelines, and refined them further:

1. Land acquisition - change of tenure for conservation purpose, including reservation and similar, funds for land purchase and conservation covenant. "Reservation and similar" was used when a land parcel was identified for purchase or swap in the approval documentation or subsequently. This was distinguished from "funds for land purchase" which required monetary contributions to a fund, to be used for land purchase; while the environmental values of the offset were specified at the time of assessment, the land parcel was not identified.

2. On-ground management - management actions that addressed threats, including rehabilitation/restoration (we have amalgamated these for ease of analysis), threat management (such as weed or fire management) and planting for fauna habitat.

3. Research - no subtypes, research included taxonomic or ecological studies and science associated with management of impacts or recovery planning (where this is included as a research offset by the regulator).

We found two additional offset types in existing approvals - Strategic funds (monetary contributions for strategic conservation outcomes; not allocated at the time of this study) and Risk management (to be applied to rectify environmental damage if this occurs).

\subsection{Offsets at different stages of implementation}

191 
In order to analyse the largest sample size of offsets, we included projects that were at different stages of completion. The requirement to implement an offset condition only occurs when the impact occurs (offset trigger), usually ground-disturbing activities or vegetation clearing. In this study, the term Past offsets includes offsets which have been implemented to the full extent planned plus those for which there was no evidence of implementation (where approval conditions indicate that the offset should have been implemented according to approval conditions). The term Current offsets includes those offsets that were in progress (where information indicates that the offset had commenced) and "unknown" (insufficient information to determine if the offset had commenced but approval dates indicate they are likely to be current) in 2015. Future offsets in this study had been approved but were not yet required at the time of the study, as the offset trigger had not occurred.

Past and current offsets included land acquisition, on-ground management and research projects, with several examples that did not fit these categories (grouped under the term "other" offset type). Strategic funds and risk management offset types were not examined in detail for this study as all examples were for future offsets.

\subsection{Methodology for categorisation according to key parameters}

Our study builds on approaches commonly used for measuring effectiveness of wetland offsets (Brown and Veneman, 2001; Environmental Law Institute, 2004; Matthews and Endress, 2008) and in restoration ecology (Hobbs, 1996; Hobbs, 2007; Society for Ecological Restoration International, 2004).

We examined the following key parameters for each offset:

a) Implementation status: the stage of offset implementation

b) Goal: whether the offset had a goal

c) Evaluation: whether effectiveness could be evaluated (e.g., complete/incomplete or completion criteria) and associated measurement and reporting of progress against goals

d) Outcome: determined the offset outcome (or likely outcome if implemented as planned).

We used publicly available information including approvals documentation (EPA reports and ministerial statements; clearing permits and decision reports; appeals information), the Offsets Register, information sourced from proponent websites or annual reporting and any other information on regulator files which would be released by request under State Freedom of Information Act 1992 (e.g. offset plans, proponent annual reporting, file notes and correspondence) to determine the approved offset area and key parameters for each offset. Google Earth imagery was used in cases where documentation was unclear, to determine if the offset trigger had occurred. If an offset package consisted of more than one offset type, the parameters above were examined for each component of the offset package.

This project relied on information available to regulators and we did not conduct any field verification of the approval-holder reporting. This reflects the legislative framework in WA where approval-holders are responsible for ensuring compliance with conditions and reporting to regulators according to approval conditions.

\subsection{Analysis of outcomes and effectiveness}

Evidence against the key parameters (see 2.4) was used to evaluate the outcome to determine whether it brought measurable, successful, long-term benefits or was likely to do so. For past 
offsets, we then determined an assessment of effectiveness for each offset, ranging from effective (retention of vegetation and successful outcome based on completion criteria), partly effective (partly successful outcome based on completion criteria), not effective (no outcome demonstrated), too early to tell, or unknown outcome. For current offsets we assessed the likely effectiveness, based on available offset project design information and progress reporting. We used a similar range of effectiveness for each offset, including likely effective (retention of vegetation likely and successful outcome based on completion criteria is likely), possibly effective (possible successful outcome if project design was adapted to allow evaluation), not effective (no outcome likely), too early to tell and unknown outcome.

Our study measured the relative effectiveness of projects against the legislative and administrative requirements of approvals. If an on-ground management or research offset measured or reported only on activities (e.g., number of plants, area over which threat management occurred or number of scientific papers published) it was not possible to evaluate the effectiveness of offsetting impacts (e.g., where impacts were to a vegetation type or habitat).

\subsection{Results}

\subsection{Successful in producing a desired or intended results}

In order to determine if the offset was successful in producing a desired or intended result, we analysed four key parameters for past and current projects (section 2.4). The results for each are presented below.

\subsubsection{Implementation status}

The number of offsets within each implementation category is shown in Table 1. Of 287 offsets analysed, seventy-four were past offsets, 134 were current offsets and seventy-nine were future offsets in 2015 (Table 1). Future offsets were not assessed further as the parameters of effectiveness could not be evaluated prior to implementation.

\subsubsection{Goals}

Most past and current offsets (85\% and 91\% respectively) had goals defined but these ranged considerably in scope and specificity. Usually the offset goal was defined as part of the assessment; for example, "rehabilitate $\mathrm{x}$ hectares at location y"; "acquire/covenant land for conservation purposes", and "improve the understanding of the biology of Species A". We did not directly examine the adequacy of the goals (i.e., to determine if they were specific, measurable, realistic, time-bound). For past offsets, $15 \%$ and for current offsets $9 \%$ did not have defined goals.

\subsubsection{Evaluation}

We determined whether 208 past and future offsets included reporting requirements and completion criteria that would allow the offset outcomes to be the evaluated. Some approvals had very specific offset conditions (such as prescription of vegetation density, survival rate over time, or weed cover), while other conditions did not contain any detail but linked to offset plans or schedules for implementation. Approval-holders were responsible for developing appropriate planning to implement offsets and any completion criteria were 
defined on a project-by-project basis to meet approval conditions. Where completion criteria were used, these usually included area of offset implemented, change in species composition over time, changes that occurred as a result of management, or change to level of understanding. This key parameter did not test whether evaluation had occurred (in fact examples of evaluation were rare), but whether the offset design ensured that it could occur.

For land acquisition offsets, goals were framed as "acquire/covenant land for conservation

298 purposes”, which was then measured as complete or incomplete; i.e., could be evaluated but not using progress towards completion criteria. Thirty-nine percent of both past and current offsets could be evaluated as being completed or incomplete, primarily land acquisition offsets but also several examples for on-ground management offsets (Fig. 1).

On a sliding scale, on-ground management and research offset types included completion criteria in project design (14\% of past offsets and $17 \%$ of current offsets); however, many did not include completion criteria but the project design could potentially be adapted to allow evaluation (27\% of past offsets and $18 \%$ of current offsets). Some offsets did not include any measures on which evaluation could occur (15\% of past offsets and $9 \%$ of current offsets).

308 We assessed the type of reporting on which an evaluation could be based, and found that $15 \%$ 309 of past offsets and $22 \%$ of current offsets reported on progress toward goals, while $45 \%$ of past offsets and 39\% were measured as complete or incomplete only. Twenty percent of past offsets and $13 \%$ of current offsets included reporting on activities (e.g., number of plants, area over which threat management occurred or number of scientific papers published) without reference to goals or completion criteria, and $20 \%$ of past offsets and $24 \%$ of current offsets had unknown reporting requirements (e.g., not specified in approval documentation or offset plans and/or no reporting could be located).

\subsubsection{Outcome}

Of the 74 past offsets, we found that $31 \%$ resulted in the retention of vegetation (land acquisition offsets), 3\% demonstrated successful outcomes according to completion criteria (on-ground management offsets) and 5\% partly demonstrated an outcome according to completion criteria (on-ground management offsets and research offsets; total 39\%; Fig. 2a). Thirty percent did not result in an offset outcome, $14 \%$ were too early to tell (i.e., measurement and reporting occurred too soon after implementation for evaluation) and 18\% had unknown outcomes (due to insufficient reporting and/or or no reporting could be located; Fig. 2a).

While current offsets were incomplete at the time of this study and thus were not considered outcomes in the same way as past offsets, we looked at existing documentation to determine what the outcomes would be if implemented as planned. For 134 current offsets, we found that $25 \%$ were likely to result in the retention of vegetation, $9 \%$ were likely to have successful outcomes according to completion criteria and 7\% could possibly be successful if the project design were adapted (Fig. 2b). For the same reasons as past offsets, 4\% were likely to result in no offset outcome, $5 \%$ were too early to tell, and for $48 \%$ the likely offset outcome was unknown (Fig 2b).

We compared the offset subtypes and found that for past offsets, land acquisition projects had the highest rate of achieving outcomes (particularly reservation and similar and funds for land purchase) and the lowest rate of unknown outcomes (Fig. 3a). Past on-ground offsets, especially rehabilitation/restoration offsets, demonstrated the highest proportion of no 
outcome, too early to tell and unknown outcome offsets (Fig 3a). For current offsets, land acquisition projects were likely to be effective through retention of vegetation, especially through the inclusion of funds for land purchase, although there was still uncertainty about the outcome for many (Fig 3b). For on-ground management offset types, there was a large proportion of unknown offset outcomes, especially for the rehabilitation and restoration projects (Fig 3b).

\subsection{Measurable, successful, long term benefits}

The outcomes for 74 past offsets were calculated as at least 2, 841 ha of land acquisition and on-ground management plus eight research projects (Table 1). This does not include additional area which could not be quantified for a number of reasons: a) measured in "currencies" other than area (such as number of trees or dollar value); b) offset areas were not quantified in available documentation, or c) where multiple offsets occurred on the same land area (e.g., where acquisition was accompanied by management, the land area was only recorded against one offset in the package to avoid double counting of the area). A summary of all past offsets included in this study (Table 2) indicates that at least 223 ha and one research project did not demonstrate an outcome; the outcomes of an additional 24 ha and four research projects were unknown due to insufficient reporting; and the outcome of 187 ha was unknown as the reporting was conducted too close to implementation to determine the outcome (too early to teli). Thus the benefit of the 74 past offsets was 2, 401 ha of land acquired for conservation purposes, 6 ha of rehabilitation/restoration that was partly demonstrated according to completion criteria and four research projects.

Given that current offsets were in progress at the time of our study, we classified them according to the offset project design and progress towards goals, but the likely outcomes were not yet demonstrated. The likely outcomes of current offsets were calculated to be 5,066 ha of land acquisition and on-ground management plus 12 research projects and additional unknown area (Table 2).

When the current offsets that were not likely to result in an outcome (at least $226 \mathrm{ha}$ ) and likely outcome unknown (974 ha and three research projects) are removed from the total area of current offset projects, this results in a likely benefit of 3, 866 ha land acquired for conservation purposes and rehabilitation/restoration plus nine research projects.

\subsection{Counterbalancing significant residual impacts or risk?}

An analysis of whether offsets adequately counterbalanced significant residual impacts relies on quantification. As part of our analysis, we attempted to calculate the impact area for past and current offsets. However, there were differences and complexities in the way in which approved impacts were recorded (e.g., whether the total impact areas vs only residual impacts were reported; where the same land area contained multiple residual impacts across different biodiversity types; and where approvals used a cost per hectare approach which provided a cost incentive to minimise the impact area). Consequently, this study cannot report on the areas of significant residual impact that lead to the imposition of offsets, and therefore cannot determine if the offsets counterbalance residual impacts. Our methodology did not examine the appropriateness of goals or completion criteria and thus did not address actual ecological effectiveness.

\subsection{Discussion}


We set out to determine if offsets imposed under WA state jurisdiction have been effective, using three key concepts - whether the offset was successful in producing desired or intended results; whether the offset brought measurable, successful, long-term benefits; and whether the benefit of the offset counterbalanced significant residual impacts or risk of a project. We examined the project planning and outcomes for 208 past and current offset projects in WA to

We used four key parameters to analyse each offset - implementation status; goals; evaluation; and offset outcome (or likely outcome if implemented as planned). Past and current offsets usually included goals and reporting requirements as part of the approval, however completion criteria were relatively rarely used. Our study showed that overall only $39 \%$ of past offsets demonstrated an outcome, while the remainder either demonstrated no outcomes (30\%) or were unknown (too early to tell 13\% and unknown outcome 18\%). The benefit of the 74 past offsets was 2, 401 ha of land acquired for conservation purposes, 6 ha of rehabilitation/restoration that was partly demonstrated according to completion criteria and four research projects. We were unable to quantify the impact area for past and current offsets and.

This study attempted to calculate the total area of residual impact which required offsetting, but data limitations meant we were unable to evaluate whether the benefits adequately counterbalanced impacts. We recognise that our analysis of effectiveness has not addressed whether offsets were adequate or appropriate and further work is required to address these types of effectiveness.

\subsection{Effective offsets}

We found that some past offsets in WA delivered the desired or intended results. Land acquisition offsets most reliably delivered offset outcomes and therefore may be considered the most effective in this study - with reservation more effective than conservation covenants and funds used for land purchase (past offsets). The land acquired for conservation purposes and rehabilitated/restored from past offsets which would not otherwise have been acquired or restored, brought measurable, successful, long-term benefits to WA. This will be added too in future as the offsets which were in progress at the time of our study are completed.

The comparative success of land acquisition offsets was partly the result demonstrating an outcome through change of tenure only, which resulted in retention of vegetation at the offset site. However, land acquisition offsets still result in net loss of native vegetation (Gibbons and Lindenmayer, 2007). Land acquisition outcomes were easier to demonstrate than either on-ground management or research offsets which required definition and meeting of completion criteria to deliver an offset outcome. Land acquisition offsets may address some threats (such as clearing or fragmentation), but they do not necessarily include on-going management and monitoring of the acquired areas to verify retention or improvement of biodiversity values over time (Walker et al., 2009; Bekessy et al., 2010). There is thus a danger that the offsets are effective on paper only.

This study found that a small number of past on-ground management (vegetation and wetland rehabilitation/restoration projects) offsets delivered an outcome and therefore were considered effective. All of the effective on-ground management offsets demonstrated project design 
which included goals or completion criteria that could be evaluated. Four flora research offsets partly demonstrated an outcome and thus were considered effective.

\subsection{Ineffective offsets}

Many past offsets did not result in an outcome and thus were not effective - including at least 30 ha not rehabilitated/restored, 71 ha not covenanted, 100 ha of land not acquired for conservation purposes, at least 22 ha of land where the threat was not adequately managed, two areas which were not planted for fauna habitat (area unknown but trees were required to be planted 2:1 for cleared trees), and research not conducted on wetland baseline fauna species.

On-ground management offsets demonstrated fewer outcomes than either land acquisition or research offsets, and we suggest this is because there are more steps to demonstrating outcomes of such projects. Within this offset type, threat management offsets (such as weed or fire management) performed poorly (consistent with findings of other authors; Maron et al., 2012), and considered ineffective when compared to other offset types.

We also found a significant issue where the final reporting for an offset was done when the rehabilitated area was immature in order to meet project and/or budget constraints (reported as outcomes too early to tell), and hence could not be evaluated. The effectiveness of $18 \%$ of past offsets was unknown, due to insufficient reporting.

The outcomes and therefore effectiveness of on-ground management offsets (and in some cases, research offsets) were often limited by ongoing threats such as damage by vehicles, herbivore grazing and seasonal or longer-term drought. Threat management offsets require benchmarking in order to demonstrate change from "before" condition, and then changes as a result of the offset; however threat management projects rarely demonstrated this kind of project design. Stochastic events such as fire, drought or extreme rainfall and longer term climate change have the potential to disrupt on-ground management offsets unless this is factored into offset design. There may be cases in which on-ground management and/or research are the best or only options, and thus is it is particularly important to improve effectiveness of these offset types.

Approximately one-third of past offsets did not result in an outcome, arising from a combination of non-implementation and failure according to completion criteria or goals; this is similar to findings by Brown et al. (2013) in New Zealand. Added to this, the outcomes of $32 \%$ of past offsets remain unknown, and so the majority of past offsets did not produce the desired or intended results, or could not be adequately assessed. Where past offsets were not successful, the loss of biodiversity has been facilitated but not compensated (Brown et al., 2013; Bekessy et al., 2010), but we were not able to provide the context or scale to determine if significant residual impacts have been counterbalanced through effective implementation of some past offsets. Consistent with Maron et al. (2016), we found that adequate information to evaluate offset effectiveness in WA was lacking.

Despite the issues with past offsets, we observed significant improvements in the clarity of offset approval conditions over the time period of our study, indicating changes in conditions approvals to address gaps. For this reason, full implementation of current offsets will likely 
result in better outcomes than past offsets. The Offsets Register allows public access to offset information and provides future opportunity to monitor implementation.

Maron et al. (2016) found that guidance was lacking (for the jurisdictions they studied) on the design of a monitoring program that would demonstrate whether or not an individual offset, or offset program as a whole, has been successful in offsetting impacts. We also found that this was the case in WA. In the following section we identify the design deficits that lead to these findings in more detail and provide some suggestions on how these could be addressed to improve offset outcomes.

\subsection{Why so many offsets were ineffective}

Our study has provided evidence of four main reasons why offsets were ineffective:

\subsubsection{Uncertainty over of compliance with conditions.}

In WA, non-compliance with approval conditions was a significant issue as $19 \%$ of past offsets demonstrated no evidence of implementation. An additional 18\% past offsets were thought to be implemented but the offset outcome was unknown - due to insufficient reporting or difficulty in locating information on regulatory agency files or other public sources. Other jurisdictions have reported the lack of adequate implementation (Brown and Veneman 2001) or lack of compliance with permit conditions (United States Government Accountability Office 2005; Dale and Gerlack 2007; Kishlinger 2008; Sudol and Ambrose 2002).

The lack of reporting on trigger activities proved a significant issue for current offsets as $47 \%$ of these were unknown, leading to uncertainty on whether the offset was required.

\subsubsection{Conditions and reporting that do not measure ecological outcomes.}

The most concerning finding of this study was that many offsets were compliant with their approval conditions, and yet did not demonstrate an outcome. This is consistent with the findings of Sudol \& Ambrose (2002), who reported that meeting regulatory requirements was not sufficient to ensure replacement of ecological function. Approval conditions must be measurable and legally enforceable, and thus conditions such as the transfer of funds to a land manager, preparation of a plan, stem density per hectare may be easily measured and reported. Conversely, the desired outcome (such as improved ecosystem condition, restoration of a vegetation or wetland community) may be difficult to translate in measurable and enforceable conditions that allow a determination of whether performance criteria have been met (Maron et al., 2012). Conditions for research offsets were often removed from outcomes as they related to improving the scientific understanding of species or ecosystems but not to management of impacts or improvement in condition.

\subsubsection{Inadequate project planning.}

Good project planning principles such as goal-setting, monitoring and evaluation of progress are readily available in the scientific or practitioner literature (e.g. Hobbs and Norton 1996; Society for Ecological Restoration International 2004). While some approval-holders undertook adequate planning for offset projects, many did not, with consequent difficulty in demonstrating outcomes. Our findings are consistent with the lack of success evident in restoration projects reported by others (Maron et al., 2102; Curran et. al, 2013). 


\subsubsection{Failure to address contingency planning.}

541

542

543

544

545

546

547

548

549

550

551

552

553

554

555

556

557

558

559

560

561

562

563

564

565

566

567

568

569

570

571

572

573

574

575

576

577

578

579

580

581

582

583

584

585

586

587

588

The risk of failure is acknowledged in published literature as the reason for requiring a larger ratio of offset area than impact area (Maron et al., 2012; Quigley and Harper, 2006; Bull et al., 2013). However, our results have shown that this reasoning is based on the assumption that at least some of the offset area was effectively implemented. Thus there are many situations that jeopardise offset outcomes but are not addressed through use of an offset ratio, such as lack of adequate implementation for the whole offset, climatic conditions or failure to address ongoing threats. This study found examples where an approval-holder has clearly made attempts at offset delivery, yet the project was not successful, and therefore the offset did not result in measurable, successful, long-term benefits.

Approval-holders are no longer responsible for the management and monitoring of offsets once the approval conditions had been met, and therefore offsets may not be managed in the longer term. In addition, if a project was planned for a specific length of time or budget, there was little capacity within the existing approval to use an adaptive management approach or to require additional resources if the project was not successful.

\subsection{How to improve effectiveness of offsets}

This research has shown that, at most, only 39\% of past offsets were effective in delivering their planned outcome, which indicates the need for improvement of offset implementation and design in Western Australia. Following on from our analysis, we make four suggestions for improvement.

\subsubsection{Timely reporting and compliance with environmental conditions.}

Approval-holders have a responsibility to ensure that their impacts are managed, and this can be done via compliance with approvals and ensuring best practice. Tracking systems can be used to ensure timely reporting of trigger events to indicate when an offset is required and then the stages of implementation. Offset conditions need to be clear and well defined to avoid ambiguity and to allow outcomes to be both achievable and enforceable.

\subsubsection{Ensure approval conditions measure ecological outcomes.}

Approval conditions should include objectives or statements about what the offset condition is designed to achieve (such as desired vegetation condition, assemblage of a vegetation type/ecological community, or reduction in impacts of threats). Such statements would provide the context for component activities, and provide direction for success criteria and subsequent monitoring and evaluation.

\subsubsection{Improve project planning for offsets.}

Adoption of a consistent approach to offset design would ensure that adequate standards of design, implementation, measurement and evaluation are incorporated as standard practice. In particular, use of completion criteria, evaluation and appropriate reporting is required to determine the outcome of offset projects. Evaluation of offset outcomes is required during and after implementation to ensure that the offset performs as expected, and that results can be fed back into the decision-making process to inform the appropriate choice of future offsets. 


\subsubsection{Include contingency planning and ongoing management.}

591

592

593

594

595

596

597

598

599

600

601

602

603

604

605

606

607

608

609

610

611

612

613

614

615

616

617

618

619

620

621

622

623

624

625

626

627

628

629

630

631

632

633

634

635

636

Given the risks and uncertainties of offset outcomes, we recommend the adoption of a formal requirement for contingency planning in offset design, to address situations where there is uncertainty of outcomes. Contingency planning could, for instance, include the establishment of a fund which could be used if reparations are required to ensure effective delivery of an offset in situations of bankruptcy and/or non-compliance, or a requirement that the offset to be in place prior to impacts, which would address risk of non-compliance and offset failure (the “savings bank" as per Bekessy et al 2010).

The ongoing and longer term management considerations of an offset need to be factored into the planning and budget. We suggest that longer term timeframes of at least 10 years are required to ensure consistent management, address threats and monitor ecological responses, dependant on the objective.

\subsection{Conclusion}

We have addressed a gap in empirical evidence of offset effectiveness (Maron et al., 2016; Maron et al., 2012), by examining the outcomes of 208 past and current offset projects undertaken between 2004 and 2015 in Western Australia. We determined whether past and current offsets were effective according to whether they have successfully produced a desired or intended results and whether the outcomes were measurable, successful, long-term benefits.

Despite improvements in policy and public availability of information on offsets, evidence from this study leads us to conclude that gaps remain in offset design and co-ordination of implementation after assessment for four main reasons:

- Uncertainty over compliance with conditions;

- Conditions and reporting which does not measure ecological outcomes;

- Inadequate project planning; and

- Failure to address contingency planning and long term management.

Some authors argue that using existing assets (e.g. native vegetation, wetlands, species habitats) as offsets will inevitably deplete biodiversity (Bekessy et al 2010), and the challenges to successful delivery of restoration offsets were found to be very significant (Maron et al 2012). Our findings indicate that land acquisition offsets stand a much higher chance of delivering an outcome when compared to on-ground management or research offsets. However, this must be balanced against continued erosion of the baseline area of native ecosystems (Gordon et al., 2015; Gibbons and Lindenmayer, 2007). Acquiring land represents a means to an end, and may not provide an effective offset in the long term. We suggest that a mechanism to ensure retention of biodiversity values (such as on-ground management) also be incorporated into future offset design.

This analysis has not touched on the degree to which offsets were adequate or appropriate (e.g., the philosophical/ethical and social challenges described by Maron et al. 2016 and Ives and Bekessey 2015) and the ecological equivalence of impacts and the outcomes. Further development of understanding of effectiveness in these areas is needed. Our findings are 
637 limited by the lack of field verification regarding the ecological value of offsets and we

638 recommend further research in this area.

639

640 While this research has focused exclusively on one jurisdiction, the results are likely to be

641 more generally relevant applicable to other jurisdictions facing similar challenges with offset

642 policy and implementation. The value of tracking the implementation and progress against

643 goals and completion criteria was been demonstrated through our research, and we have

644 provided some suggestions on ways in which offsets would benefit from better project

645 planning.

646

647

\subsection{Acknowledgements}

648

649 This research does not represent the views of any of the departments that provided access to

650 data.

651

652

This research formed part of a Masters of Science undertaken by JEM, and partly funded via a 653

654 scholarship from the WA Department of Parks and Wildlife and predecessor departments. The authors also wish to thank the Office of the Environmental Protection Authority, Department of Environment Regulation, Department of Parks and Wildlife and Department of Mines and Petroleum for access to data, advice, assistance and support throughout.

658

659

660

RJH and LEV acknowledge funding support from the Australian Research Council Centre of

661 Excellence in Environmental Decisions.

662 All authors acknowledge the comments on an earlier draft of this paper provided by three

663 anonymous reviewers. 
664

665

666

667

668

669

670

671

672

673

674

675

676

677

678

679

680

681

682

683

684

685

686

687

688

689

690

691

692

693

694

695

696

697

698

699

700

701

702

703

704

705

\subsection{References}

Aiama, D., Edwards, S., Bos, G., Ekstrom, J., Krueger, L., Quetier, F., Savy, C., Semroc, B., Sneary, M., Bennun, L., 2015. No net loss and positive impact approaches for biodiversity: exploring potential application of these approaches in the commercial agriculture and forestry sectors. IUCN, Gland, Switzerland.

Bekessy, S.A., Wintle, B.A., Lindenmayer, D.B., McCarthy, M.A., Colyvana, M., Burgman, M.A., Possingham, H.P., 2010. The biodiversity bank cannot be a lending bank. Conservation Letters 3, 151-158.

Brown, S.C., Veneman, P.L.M., 2001. Effectiveness of compensatory wetland mitigation in Massachusetts, USA. Wetlands 2, 508-518.

Brown, M.A., Clarkson, B.D., Barton, B.J., Joshi, C., 2013. Ecological compensation: an evaluation of regulatory compliance in New Zealand. Interantional Association for Impact Assessment 31, 34-44.

Bull, J.W., Suttle, K.B., Gordon, A., J.Singh, N., Milner-Gulland, E.J., 2013. Biodiversity offsets in theory and practice. Oryx 47,369-380.

Burgin, S., 2008. BioBanking: an environmental scientist's view of the role of biodiversity banking offsets in conservation. Biodiversity Conservation, 807-816.

Business and Biodiversity Offsets Programme, 2009. Biodiversity Offset Implementation Handbook. Business and Biodiversity Offsets Programme, Washington

Business and Biodiversity Offsets Programme, 2012. Standard on Biodiversity Offsets. Business and Biodiversity Offsets Programme, Washington.

Dale, L., Gerlak, A., 2007. It's all in the numbers: Acreage tallies and environmental program evaluation. Environmental Management 39, 246-260.

Environment and Communications References Committee, 2014. The Senate Environment and Communications References Committee Environmental Offsets. Commonwealth of Australia 2014, Canberra.

Environmental Law Institute, 2004. Measuring Mitigation: A review of the science for compensatory mitigation perfromance standards. Environmental Law Institute, Washington.

Environmental Protection Authority, 2006. Position Statement 9: Environmental Offsets.EPA, Perth.

Environmental Protection Authority, 2008. Guidance for the assessment of environmental factors - Environmental Offsets Biodiversity. EPA, Perth.

Environmental Protection Authority, 2013. Environmental Assessment Guideline for Recommending environmental conditions. EPA, Perth.

Fallding, M., 2014. Biodiversity offsets: Practice and promise. Environmental and Planning Law Journal 31, 11-33.

Gibbons, P., Lindenmayer, D.B., 2007. Offsets for land clearing: no net loss or the tail wagging the dog? Ecological Management \& Restoration 8, 26-31.

Goncalves, B., Marques, A., Soares, A.M.V.D.M., Pereira, H.M., 2015. Biodiversity offsets: 
from current challenges to harmonized metrics. Science Direct 14, 61-67.

Gordon, A., Bull, J.W., Wilcox, C., Maron, M., 2015. Perverse incentives risk undermining biodiversityoffset policies. Journal of Applied Ecology 52, 532-537.

Gordon, A., Langford, W.T., Todd, J.A., White, M.D., Mullerworth, D., 2011. Assessing the impacts of biodiversity offset policies. Environment Modelling and Software 26, 14811148.

Government of WA, 2011. WA Environmental Offsets Policy Government of WA, Perth

Government of Western Australia, 2014. WA Environmental Offsets Guidelines. Government of Western Australila, Perth.

Hobbs, R.J. Norton, D., 1996. Towards a conceptual framework for restoration ecology. Restoration Ecology 4, 93-110.

Hobbs, R.J., 2007. Setting effective and realistic restoration goals: Key directions for research. Restoration Ecology 15, 354-357.

International Association for Impact Assessment, 2009. What is impact assessment? International Association for Impact Assessment, Fargo.

Ives, C., Bekessy, S., 2015. The ethics of offsetting nature. Frontiers in Ecology and the Environment 13, 563-573.

Kishlinger, R.L., 2008. Success of wetland mitigation projects. National Wetlands Newsletter 30, 14-16.

Maron, M., Hobbs, R.J., Moilanen, A., Matthews, J.W., Christie, K., Gardner, T.A., Keith, D., A, Lindenmayer, D.B., McAlpine, C., A, 2012. Faustian bargains? Restoration realities in the context of biodiversity offset policies. Biological Conservation 155, 141-148.

Maron, M., Gordon, A., Mackey, B.G., Watson, J.E.M., 2015. Conservation: Stop misuse of biodiversity offsets. Nature 22, 401-403.

Maron, M., Ives, C., Kujala, H., Bull, J., Maseyk, F., Bekessy, S., Gordon, A., Watson, J., Lentini, P., Gibbons, P., Possingham, H., Hobbs, R., Keith, D., Wintle, B., Evans, M., 2016. Taming a wicked problem: resolving controversies in biodiversity offseting. BioScience doi:10.1093/biosci/biw038.

Matthews, J.W., Endress, A.G., 2008. Performance criteria, compliance Success, and vegetation development in compensatory mitigation wetlands. Environmental Management 41, 130141.

McKenny, B., Kiesecker, J.M., 2010. Policy Development for biodiversity offsets: A review of offset frameworks. Environmental Management 45, 165-176.

Moreno-Mateos, D., Power, M.E., Comin, F., Yockteng, R., 2012. Structural and Functional Loss in Restored Wetland Ecosystems. PLoS Biology 10.

Moreno-Mateos, D., Maris, V., Béchet, A., Currane, M., 2015. The true loss caused by biodiversity offsets. Biological Conservation 192, 552-559.

Myers, N., Mittermeier, R.A.M., Cristina G., da Fonseca, G.A.B., Kent, J., 2000. Biodiversity hotspots for conservation priorities. Nature, 853-858.

Norris, P., 2014. Seeking balance: The promise and reality of biodiversity offsetting. Environmental Planning and Law Journal, 137-147. 
Quality: a retrospective assessment. The Australian Journal of Agricultural and Resource Economics 54, 437-456.

Pickett, E.J., Stockwell, M.P., Bower, D.S., Garnham, J.I., Pollard, C.J., Clulow, J., Mahony, M.J., 2013. Achieving no net loss in habitat offset of a threatened frog required high offsetratio and intensive monitoring. Biological Conservation 157, 156-162.

Pope, J., Bond, A., Morrison-Saunders, A., Retief, F., 2013. Advancing the theory and practice of impact assessment: setting the research agenda. Environmental Impact Assessment Review 41, 1-9.

Quétier, F., Lavorel, S., 2011. Assessing ecological equivalence in biodiversity offset schemes: Key issues and solutions. Biological Conservation 144, 2991-2999.

Quigley, J.T., Harper, D.J., 2006. Effectiveness of fish habitat compensation in Canada in achieving no net loss. Environmental Management 37, 351-366.

Society for Ecological Restoration International, 2004. The SER International Primer on Ecological Restoration. Society for Ecological Restoration International, Tuscon.

Sudol, M.F., Ambrose, R.F., 2002. The US Clean Water Act and Habitat Replacement: Evaluation of Mitigation Sites in Orange County, California, USA. Environmental Management 30, 727-734.

Teal, J.M., 2011. US wetland protection and restoration: have we made a difference? Ecological Restoration 22, 29-34.

ten Kate, K., Bishop, J., Bayon, R., 2004. Biodiversity offsets: Views, experience, and the business case, IUCN, Gland, Switzerland and Cambridge, UK and Insight Investment, London UK.

United States Government Accountability Office, 2005. Wetlands Protection Corps of Engineers does not have effective oversight approach to ensure that compensatory mitigation is occurring, In Report to the Ranking Democrative Member, Committee on Transportation and Infrastructure, House of Representatives. United States General Accounting Office, Washington.

Vanderduys, E.P., Reside, A.E., Grice, A., Rechetelo, J., 2016. Addressing potential cumulative impacts of development on threatened species: the case of the endangered black-throated finch. PLoS ONE 11.

Walker, S., Brower, A.L., Stephens, R.T.T., Lee, W.G., 2009. Why bartering biodiversity fails. Conservation Letters 2, 149-157. 


\section{TABLES}

Table 1: The number of offsets types within each implementation status (past, current and future offsets) assessed during this study that were approved in Western Australia, between 2004 to February 2015, under the State Environmental Protection Act 1986 (EP Act).

\begin{tabular}{llll}
\hline Offset Type & Past offsets & Current offsets & Future offsets \\
\hline
\end{tabular}

Land acquisition

Conservation covenant

8

12

5

Funds for land purchase

12

21

4

Reservation \& similar

9

Subtotal

29

18

8

On-ground management

Rehabilitation/restoration $\quad 26$

Planting for fauna habitat 2

$51 \quad 17$

17

\begin{tabular}{llll} 
Threat management & 8 & 19 & 14 \\
\hline Subtotal & 36 & 67 & 25 \\
\hline Research & 8 & 12 & 10
\end{tabular}

Other

Other

Risk management/

contingency

Strategic fund

Subtotal

1

12

11

38

0

Total (287)

0

Q

0

4

788

789

790 
Table 2. The number and amount of past offsets outcomes for conservation, rehabilitation or research, assessed in terms of effectiveness (based on reporting requirements and completion/success criteria). The offsets assessed during this study that were approved in Western Australia, between 2004 to February 2015, under the State Environmental Protection Act 1986 (EP Act).

\begin{tabular}{|c|c|c|c|c|c|c|c|c|c|c|c|}
\hline & & \multicolumn{2}{|c|}{$\begin{array}{l}\text { Successful outcome } \\
\text { (retention of } \\
\text { vegetation }+ \\
\text { completion criteria) }\end{array}$} & \multicolumn{2}{|c|}{$\begin{array}{c}\text { Partly } \\
\text { successful } \\
\text { (completion } \\
\text { criteria) } \\
\end{array}$} & \multicolumn{2}{|c|}{$\begin{array}{c}\text { Too early to } \\
\text { tell }\end{array}$} & \multicolumn{2}{|c|}{ Unknown outcome } & \multicolumn{2}{|c|}{$\begin{array}{l}\text { No outcome } \\
\text { demonstrated }\end{array}$} \\
\hline & & $\#$ & Amount & $\#$ & Amount & $\#$ & Amount & $\#$ & Amount & $\#$ & Amount \\
\hline \multirow[b]{2}{*}{$\begin{array}{l}\text { Land } \\
\text { acquisition }\end{array}$} & $\begin{array}{l}\text { Conservation } \\
\text { covenant }\end{array}$ & 4 & 40 ha & - & - & - & - & - & - & 4 & 71 ha \\
\hline & $\begin{array}{l}\text { Funds for land } \\
\text { purchase + } \\
\text { Reservation \& } \\
\text { similar }\end{array}$ & & 2,331ha & - & - & - & - & - & - & 2 & 100 ha \\
\hline \multirow{4}{*}{$\begin{array}{l}\text { On-ground } \\
\text { management }\end{array}$} & $\begin{array}{l}\text { Threat } \\
\text { management }\end{array}$ & & - & - & - & 3 & 87 ha & 2 & Unknown & 3 & $\begin{array}{c}\text { At least } 22 \\
\text { ha }\end{array}$ \\
\hline & $\begin{array}{l}\text { Rehabilitation/ } \\
\text { restoration }\end{array}$ & 2 & & 1 & 6ha & 7 & 100 ha & 7 & 24 ha & 9 & $\begin{array}{c}\text { At least } 30 \\
\text { ha }\end{array}$ \\
\hline & $\begin{array}{l}\text { Planting for } \\
\text { fauna habitat }\end{array}$ & - & & & - & - & - & - & - & 2 & $\begin{array}{c}\text { Tree } \\
\text { planting } \\
\text { ratio 2:1 }\end{array}$ \\
\hline & Other & - & - & & - & - & - & - & - & 1 & Unknown \\
\hline Research & & - & - & 3 & $\begin{array}{l}\text { flora } \\
\text { research }\end{array}$ & _ & - & 4 & $\begin{array}{c}2 \text { taxonomic } \\
\text { studies }+ \\
\text { ethno- } \\
\text { botanical study } \\
+ \text { management } \\
\text { plan }\end{array}$ & 1 & $\begin{array}{c}\text { Baseline } \\
\text { wetland } \\
\text { study }\end{array}$ \\
\hline Total & & 25 & 2, 401 ha & 4 & $\begin{array}{c}6 \text { ha }+3 \\
\text { research } \\
\text { projects }\end{array}$ & $\begin{array}{l}1 \\
0\end{array}$ & & 13 & $\begin{array}{c}24 \text { ha }+4 \\
\text { research } \\
\text { projects }\end{array}$ & 22 & $\begin{array}{c}223 \text { ha }+ \\
\text { unknown } \\
\text { area }+1 \\
\text { research } \\
\text { project }\end{array}$ \\
\hline
\end{tabular}


805

Table 3. The number and amount of current offsets outcomes for conservation, rehabilitation or research assessed in terms of likely effectiveness (based on information available for reporting requirements and completion/success criteria). The offsets assessed during this study that were approved in Western Australia, between 2004 to February 2015, under the State Environmental Protection Act 1986 (EP Act); the current offsets were in progress or were likely to be current in 2015.

\begin{tabular}{|c|c|c|c|c|c|c|c|c|c|c|c|}
\hline & & \multicolumn{2}{|c|}{$\begin{array}{c}\text { Success likely } \\
\text { (retention of } \\
\text { vegetation }+ \\
\text { completion criteria) }\end{array}$} & \multicolumn{2}{|r|}{$\begin{array}{l}\text { Possible } \\
\text { success if } \\
\text { adapted }\end{array}$} & \multicolumn{2}{|c|}{$\begin{array}{l}\text { Too early to } \\
\text { tell }\end{array}$} & \multicolumn{2}{|c|}{$\begin{array}{c}\text { Unknown } \\
\text { outcome likely }\end{array}$} & \multicolumn{2}{|c|}{$\begin{array}{c}\text { No outcome } \\
\text { likely }\end{array}$} \\
\hline & & $\#$ & Amount & $\#$ & Amount & $\#$ & Amount & $\#$ & Amount & $\#$ & Amount \\
\hline \multirow[b]{2}{*}{$\begin{array}{l}\text { Land } \\
\text { acquisition }\end{array}$} & $\begin{array}{l}\text { Conservation } \\
\text { covenant }\end{array}$ & 5 & 73 ha & - & - & - & - & 5 & 500 ha & 2 & 16 ha \\
\hline & $\begin{array}{l}\text { Funds for land } \\
\text { purchase }+ \\
\text { Reservation \& } \\
\text { similar }\end{array}$ & & 3173 ha & - & - & 2 & unknown & 8 & 111 ha & - & - \\
\hline \multirow{4}{*}{$\begin{array}{l}\text { On-ground } \\
\text { management }\end{array}$} & $\begin{array}{l}\text { Threat } \\
\text { management }\end{array}$ & & - & 5 & unknown & 3 & 91 ha & 10 & unknown & 1 & unknown \\
\hline & $\begin{array}{l}\text { Rehabilitation/ } \\
\text { restoration }\end{array}$ & 5 & & 1 & 2 ha & 1 & 19 ha & 28 & 351 ha & 3 & 210 ha \\
\hline & $\begin{array}{l}\text { Planting for } \\
\text { fauna habitat }\end{array}$ & 1 & 470 & & - & 1 & unknown & 8 & 12 ha & - & - \\
\hline & Other & - & - & & unknown & 1 & unknown & 2 & unknown & - & - \\
\hline Research & & 6 & $\begin{array}{l}\text { wetlands } \\
\text { research + } \\
\text { WAMSI }\end{array}$ & & $\begin{array}{l}\text { flora } \\
\text { research }\end{array}$ & 1 & $\begin{array}{l}\text { fauna } \\
\text { research }\end{array}$ & 3 & $\begin{array}{l}\text { wetland } \\
\text { restoration }\end{array}$ & - & - \\
\hline Totals & & 46 & $\begin{array}{c}3,756 \text { ha }+6 \\
\text { research } \\
\text { projects }\end{array}$ & 9 & $\begin{array}{l}\text { Unknown } \\
\text { area }+2 \\
\text { research } \\
\text { projects }\end{array}$ & & $\begin{array}{l}110 \text { ha }+ \\
\text { unknown } \\
\text { area }+ \\
\text { fauna } \\
\text { research }\end{array}$ & 64 & $\begin{array}{l}974 \text { ha }+3 \\
\text { wetland } \\
\text { restoration } \\
\text { projects }\end{array}$ & 6 & $\begin{array}{c}226 \text { ha }+ \\
\text { unknown } \\
\text { area }\end{array}$ \\
\hline
\end{tabular}


810

811

812

813

814

815

816

817

818

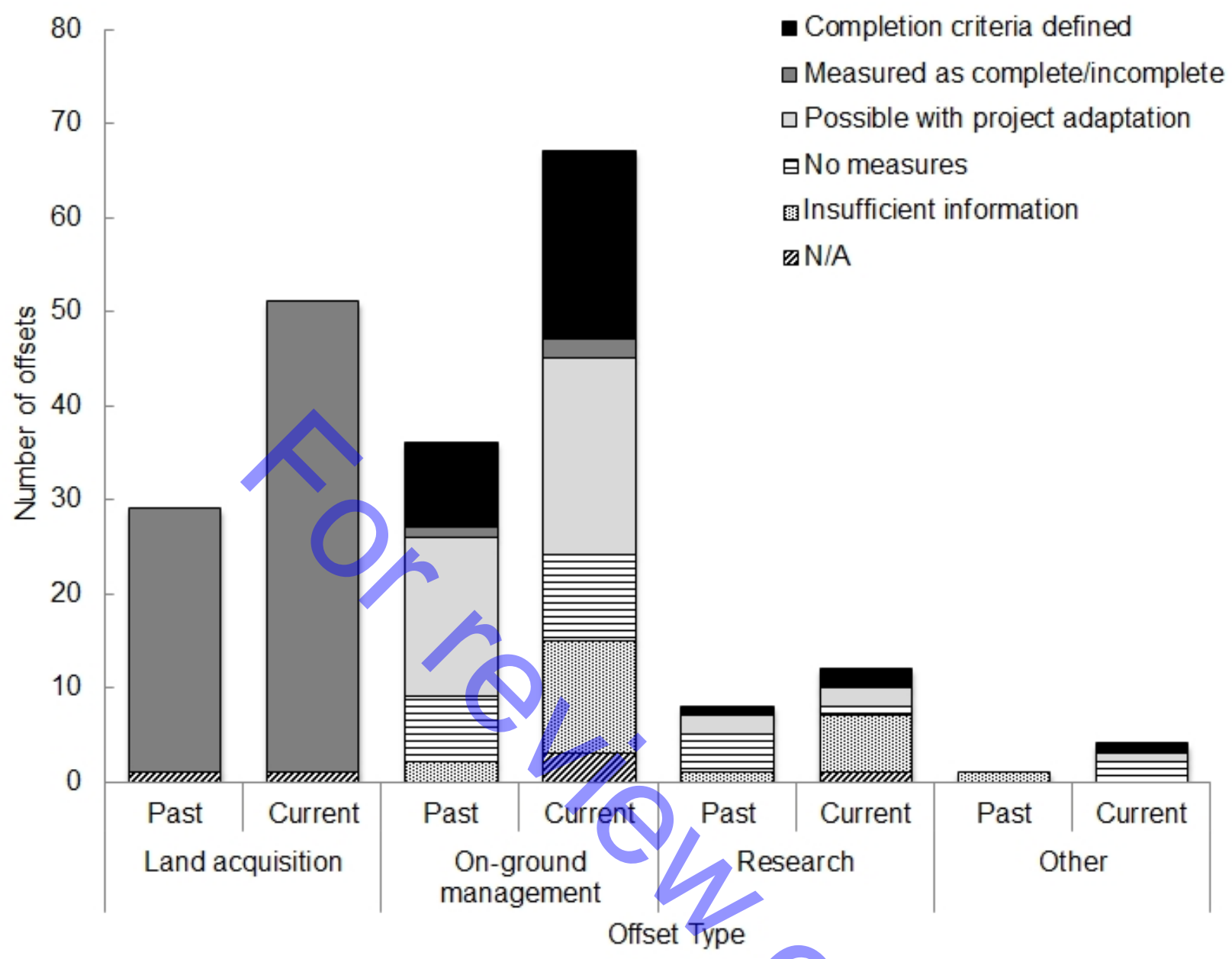

Fig. 1. The number of past and current offsets $(n=208)$, based on offset type, that included reporting requirements and/or completion/success criteria that would allow the offset outcome to be evaluated for effectiveness. All offsets included were approved in Western Australia between 2004 - February 2015 under the State Environmental Protection Act 1986 (EP Act). 




Fig 2. The number of a) past offsets $(n=74)$ and $b)$ current offsets $(n=134)$ among different offset types with levels of successful outcomes, or likely outcomes, according to Western Australia between 2004 - February 2015 under the State Environmental Protection Act 1986 (EP Act). 
a) Past offsets

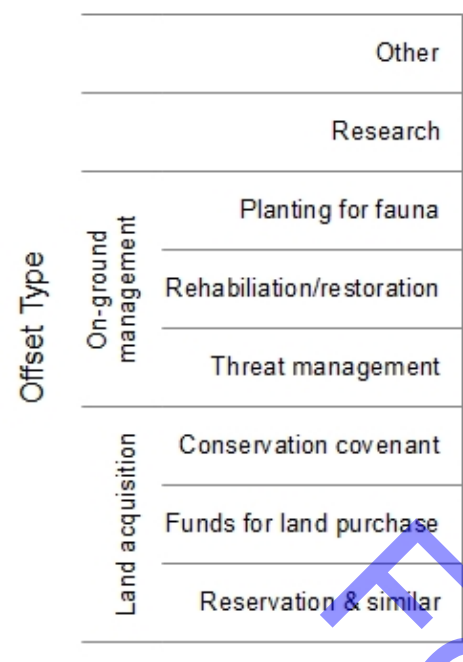

-Retention of vegetation

口Successful (completion criteria)

$\square$ Partly successful (completion criteria)

曰No outcome demonstrated

aUnknown outcome

వToo early to tell

b) Current offsets

$0 \quad 10$

Other

至

20

30

40

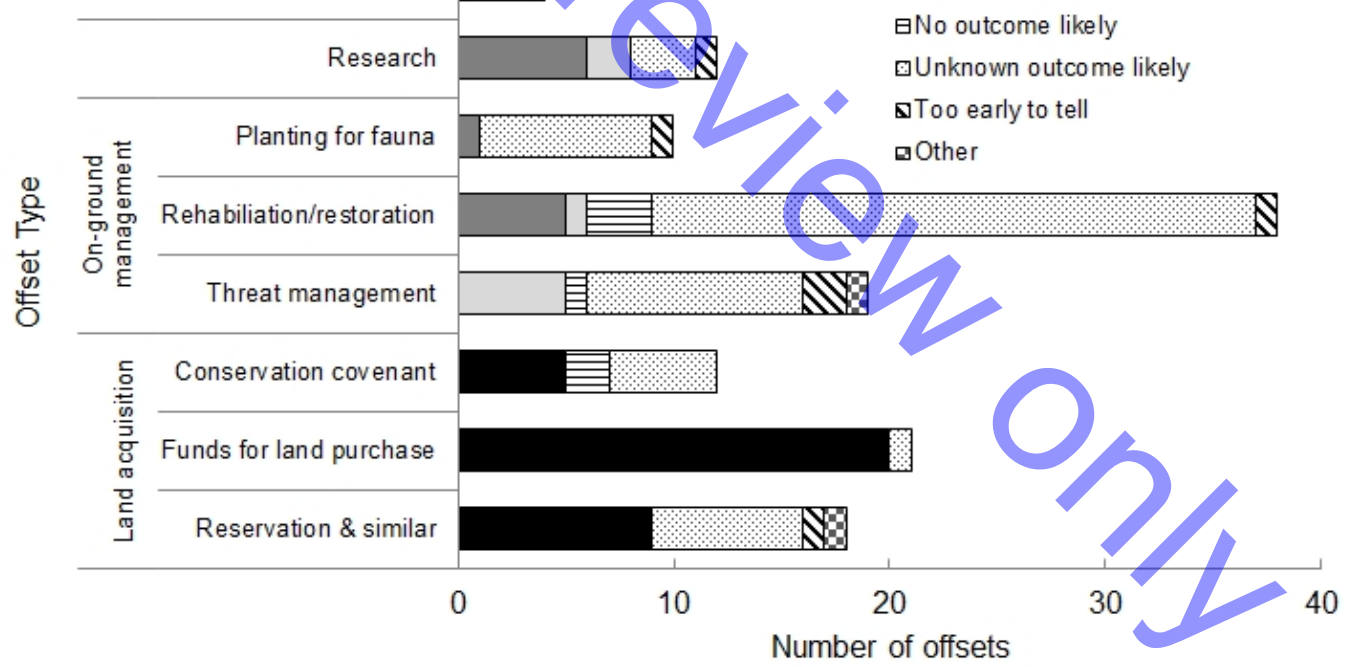

Fig. 3. The number of a) past offsets $(n=74)$ and $b)$ current offsets $(n=134)$ among different offset types and sub-types with levels of successful outcomes, or likely outcomes, according to completion/success criteria and reporting requirements. All offsets included were approved in Western Australia between 2004 - February 2015 under the State Environmental Protection Act 1986 (EP Act). 